\title{
Influence of Cooling Rate on Nature and Morphology of Intercellular Precipitates in Si-Mo Ductile Irons
}

\author{
Mervat Youssef ${ }^{1, a,{ }^{*}}$, Adel Nofal ${ }^{1, b}$ and Abdelhamid Hussein ${ }^{2, c}$ \\ ${ }^{1}$ Central Metallurgical R\&D Institute, Cairo, Egypt \\ ${ }^{2}$ Cairo University, Faculty of Engineering, Cairo, Egypt \\ ausf.mervat@gmail.com, badelnofal@hotmail.com, ca.hussein@yahoo.com
}

Keywords: Si-Mo, Thin-Wall, Intercellular Carbides, Eutectic Carbides.

\begin{abstract}
This work is designed to better understand the influence of cooling rate on the nature and morphology of intercellular precipitates in Silicon-Molybdenum ferritic ductile iron (SiMo). Plates of 3,6,9 mm thickness were cast in greensand and investment casting molds to give a wide spectrum of cooling rates. It was found that at higher cooling rates, the intercellular regions have a lamellar structure typical of pearlite. With decreasing cooling rates, the precipitate contains complex (Fe-Mo-Si) carbides of fine spheroidal or rod-like structure surrounding the eutectic carbides.

Intensive Scanning Electron Microscopy with Energy Dispersive Spectroscopy (SEM/EDS) and Optical Microscopy (OM) investigations showed that the eutectic carbides are mainly (Fe, Mo, $\mathrm{Si})$ $\mathrm{C}$ containing up to $48 \%$ Mo, whereas the fine precipitates contain lower Mo-contents. Both carbide types did not show to have a strict stoichometric composition. The solidification and solid-state transformation path was determined using both phase diagram calculated from Thermo-Calc software as well as Differential Scanning Calorimetry (DSC).
\end{abstract}

\section{Introduction}

Over the past few decades, SiMo ductile irons have been finding increasing applications for high temperature automotive components such as exhaust manifolds and turbocharger housings [1-3]. The oxidation resistance, high temperature strength and dimensional stability are required to cope with the increasingly higher temperature internal combustion exhaust gases (may reach up to $880^{\circ} \mathrm{C}$ ) associated with improving the Internal Combustion Engine (ICE) efficiency [4-6].

There are material specifications typically impose limits on pearlite content in ferritic ductile irons to avoid the alloy dilation and growth associated with decomposition of the pearlite cementite at high operation temperatures [2]. SiMo ductile irons have an advantage over high - Si ductile iron containing pearlite and the presence of a $\mathrm{Fe}_{2} \mathrm{MoC} / \mathrm{M}_{6} \mathrm{C}$ type carbide phases with higher thermal stability, leads to remarkable dimensional stability up to $925^{\circ} \mathrm{C}$ [2].

Casting experiments and solidification modeling have shown, that the shrinkage tendency of high Si-Mo containing 4-6\% Mo can be controlled in the same level as that of regular SiMo, using suitable C.E (4.35-4.85), depending upon the critical thickness of the casting [3].

The impact of the section thickness and cooling rate of the castings on the cell boundary carbide precipitation in SiMo alloys has been scarcely dealt with in the literature. There is a need to better understand the nature and morphology of intercellular precipitates in SiMo ductile iron. The main objectives of this work, therefore, is to investigate the influence of the cooling rate of thin-wall SiMo castings of section thickness ranging from 3-9 $\mathrm{mm}$ and cast in greensand or investment casting molds. 


\section{Experimental Procedure}

\section{Samples Preparation}

Melting of the experimental heats was carried out in a medium frequency $(1000 \mathrm{~Hz})$ acid lined induction furnace of $100 \mathrm{~kg}$ capacity. The metallic charge used to prepare the base molten iron consisted of high purity (Sorel) pig iron, steel scrap, ferrosilicon $75 \%$, Ferro-molybdenum $60 \%$ as well as carburizing material. The molten iron was tapped at $1500^{\circ} \mathrm{C}$, then treated with $1.4 \%$ of $\mathrm{Mg}-\mathrm{FeSi}$ spheroidizing alloy containing $9-10 \% \mathrm{Mg}$ and inoculated with $(1.2-2 \% \mathrm{Ce})$ inoculant.

The pattern was used to cast $200 \times 150 \mathrm{~mm}$ plates with thickness of 3,6 and $9 \mathrm{~mm}$. The chemical composition of the SiMo ductile iron samples poured is as follows, in wt. percent: C: $2.61 \%$, Si: 5.07\%, Mo: 0.7\%, Mn: 0.26\%, P: 0.035\%, S: 0.012\%, Mg: 0.037\%.

\section{Metallographic Investigation}

Metallographic examinations were carried out on samples, etched with $2 \%$ Nital. OM at high resolution and SEM FEI-Quaunta ${ }^{\mathrm{TM}}$ was used for further investigation and analysis of eutectic carbides and the fine precipitate phases formed in the vicinity of the cell boundaries.

\section{Solidification and Solid-State Transformation Path}

The Fe-Mo-C phase diagram of the alloy investigated throughout this work ( $\mathrm{Si}: 5$ and Mo: 0.7) was calculated using "Thermo-Calc 2017a" data base: TCFE 8-V8.1 and the volume fraction of phases as well as transformation temperatures were calculated.

However, for more accurate determination of the phase transformation temperatures, the data obtained from the calculated phase diagram were compared to those measured using the Differential Scanning Calorimetry (DSC). Throughout this investigation, Differential Scanning Calorimeter NETSCH STA $409 \mathrm{C} / \mathrm{CD}$ was used, with cooling rate of $30^{\circ} \mathrm{C} / \mathrm{min}$.

\section{Results \& Discussions}

\section{Solidification and Solid-State Transformation Sequence}

Thermo-Calc phase diagram of $0.7 \%$ Mo section of the Fe-Mo-C is shown in fig (1-a,b), which illustrates the formation of carbide phases in equilibrium with austenite (FCC) and ferrite (BCC) on cooling from the liquidus line $\left(\sim 1270^{\circ} \mathrm{C}\right)$ to the room temperature.

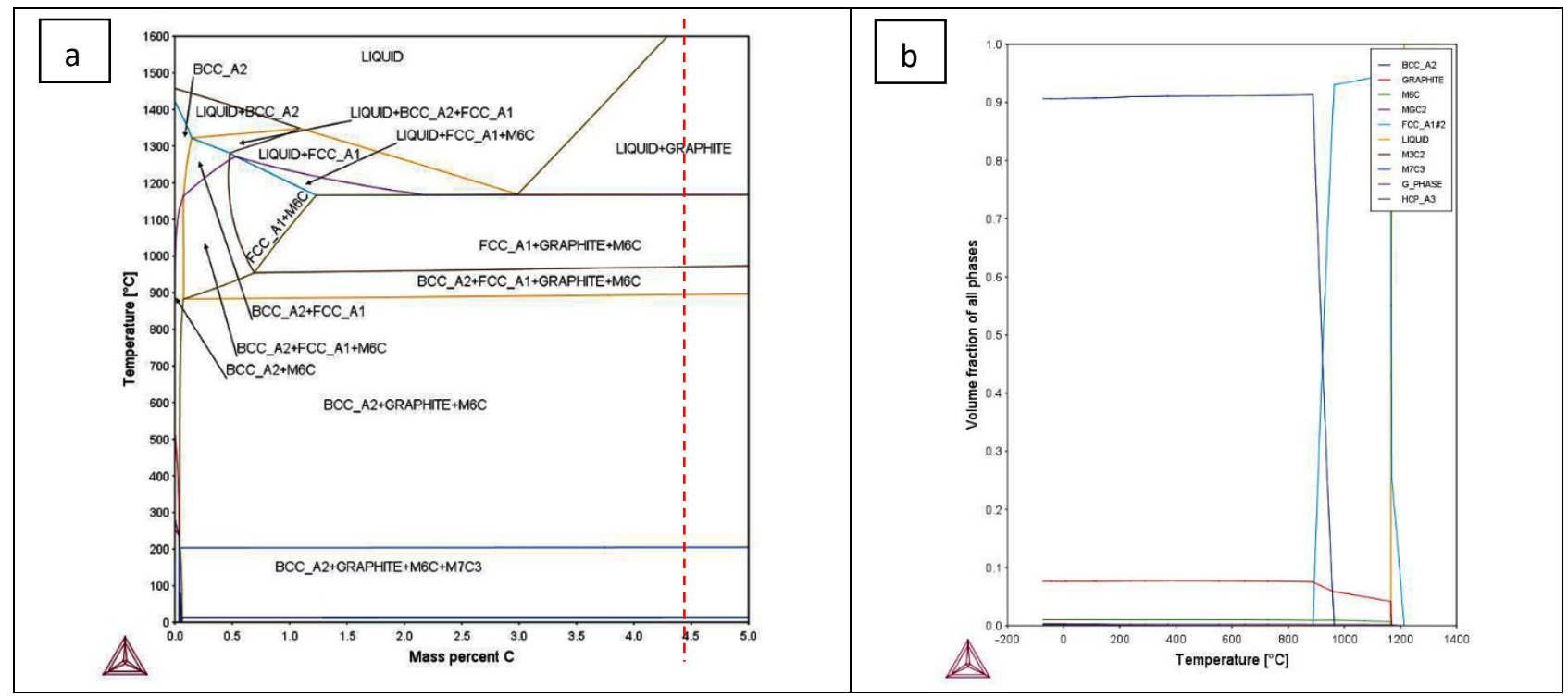

Fig 1: (a) Thermo-Calc phase diagram of SiMo (the dashed line represent the C.E of produced alloy $\approx 4.3$, (b) volume fraction of all phases formed 
Figure (2) shows DSC curve illustrating the sequence of phase transformations during cooling at $30^{\circ} \mathrm{C} / \mathrm{min}$ of a SiMo sample cast in $3-\mathrm{mm}$ thick plates.

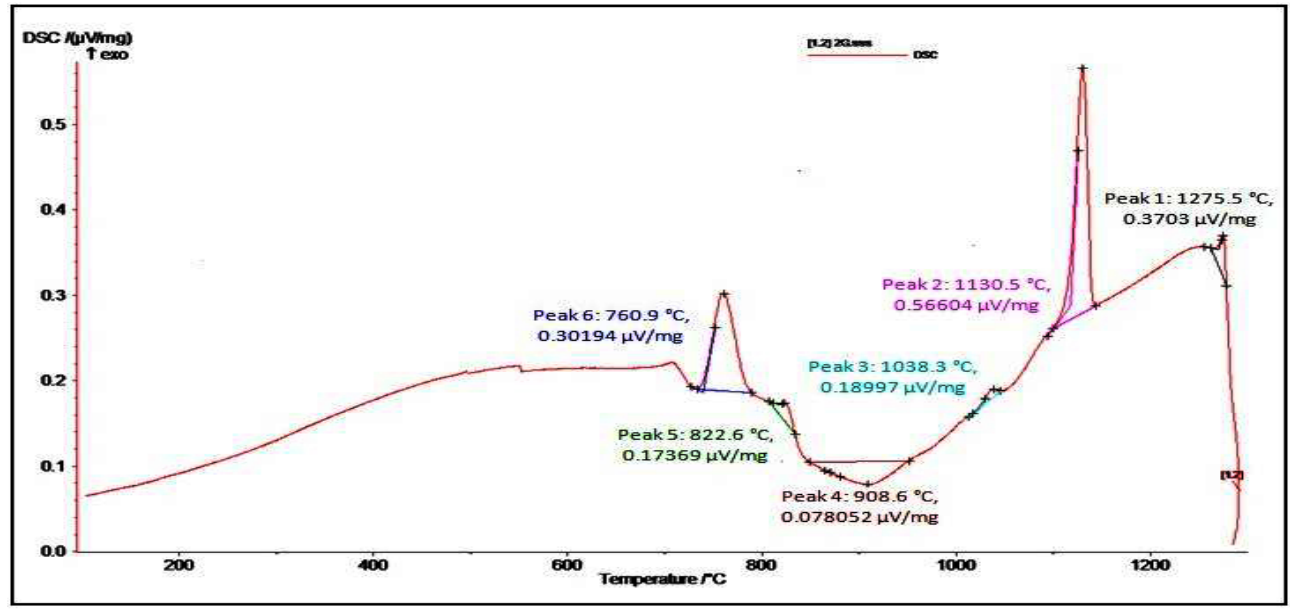

Fig 2: DSC cooling curve of 3mm- green sand SiMo

Comparing data obtained from the Thermo-Calc phase diagram shown in fig $(1, \mathrm{a})$ with the DSC peaks, the solidification and solid-state phase transformations of the alloy could be summarized in table 1 .

Table 1: Transformation temperatures revealed from the Thermo-Calc phase diagram vs those predicted from the peaks of the DSC

\begin{tabular}{|c|c|c|c|}
\hline Transf. & $\begin{array}{c}\text { Approx. Temp. } \\
\text { revealed from the } \\
\text { phase diagram }\end{array}$ & $\begin{array}{c}\text { Corresponding } \\
\text { peaks in DSC curve }\end{array}$ & $\begin{array}{c}\text { Solidification and solid-state reactions } \\
\text { during cooling }\end{array}$ \\
\hline 1 & 1200 & 1275.0 & Liquidus: $\mathrm{L} \rightarrow \mathrm{L}+\gamma$ \\
\hline 2 & 1170 & 1130.5 & Eutectic reaction: $\mathrm{L} \rightarrow \gamma+\mathrm{Gr}+\mathrm{M}_{6} \mathrm{C}$ \\
\hline 3 & 960 & 1038.3 & $\begin{array}{c}\text { Eutectoid reaction }(\mathrm{start}): \gamma+\mathrm{Gr}+\mathrm{M}_{6} \mathrm{C} \rightarrow \\
\gamma+\alpha+\mathrm{Gr}+\mathrm{M}_{6} \mathrm{C}\end{array}$ \\
\hline 4 & 900 & 908.6 & $\begin{array}{c}\text { Eutectoid reaction }(\mathrm{end}): \gamma+\alpha+\mathrm{Gr}+\mathrm{M}_{6} \mathrm{C} \\
\rightarrow \alpha+\mathrm{Gr}+\mathrm{M}_{6} \mathrm{C}\end{array}$ \\
\hline 5 & - & 822.6 & $\begin{array}{c}\text { Precipitation of intercellular components: } \alpha \\
+\mathrm{Gr}+\mathrm{M}_{6} \mathrm{C} \rightarrow \alpha+\mathrm{Gr}+\mathrm{M} 6 \mathrm{C}+\mathrm{Fe} \mathrm{M}_{2} \mathrm{C}\end{array}$ \\
\hline 6 & - & 760.9 & $\begin{array}{c}\text { Curie temperature: } \alpha \text { non magnetic } \rightarrow \alpha \\
\text { magnetic }\end{array}$ \\
\hline 7 & 200 & - & Precipitation of $\mathrm{M}_{7} \mathrm{C}_{3}$ in $\alpha$ \\
\hline
\end{tabular}

It should be noticed that the phase transformations displayed by the DSC curve confirm those suggested by the Thermo-Calc calculated phase diagram. This confirmation however is more qualitative, with some deviations in the transformation temperatures, which is expected. The phase diagram is based on equilibrium conditions, whereas DSC curve is generated at cooling rates of $30^{\circ} \mathrm{C} / \mathrm{min}$.

\section{Microstructure of SiMo with Different Section Thickness}

\section{Specimens Cast in Greensand Molds}

Fig 3 shows the microstructure of SiMo ductile iron cast in greensand mold with thickness 3, 6 and $9 \mathrm{~mm}$. The microstructures generally consist of spheroidal graphite with varying amounts of cellboundary precipitates in a ferritic matrix. At small magnification of this figure, the intercellular precipitates are similar to pearlite, and its formation at the cell boundary zones in increasing 
amounts with decreasing the solidification rate (or increasing the section thickness) is an indication of segregation related phenomena.

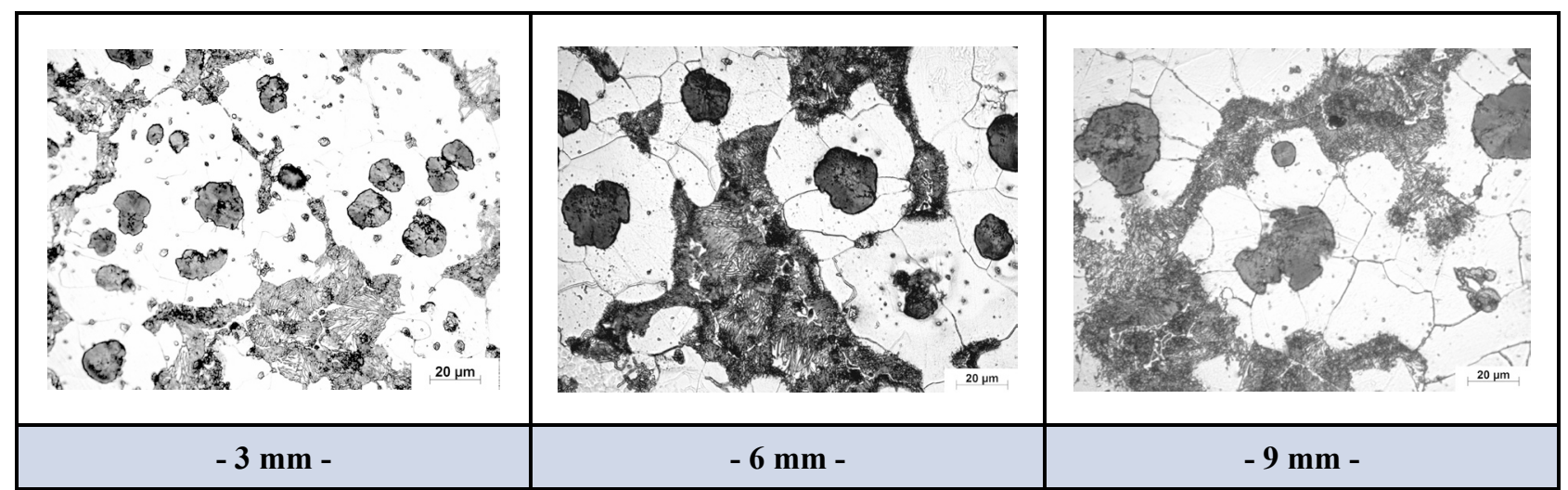

Fig 3: Microstructures of SiMo casting of 3, 6 and 9mm cast in greensand molds

\section{Nature of Eutectic Carbides}

From the phase diagram calculated using the Thermo-Calc software, the eutectic carbides are suggested to be of $\mathrm{M}_{6} \mathrm{C}$-type. The micrographs shown in fig 4, show that those carbides are of relatively coarse sizes with Chinese Script morphology. It may be noticed, that the Mo-content in the eutectic particles covers a wide range from $3.60-42.70 \%$ with varying levels of $\mathrm{Si}$, which suggests that those particles may cover a wide spectrum of (Fe, Mo, Si) carbides of the $\mathrm{M}_{6} \mathrm{C}$-type.

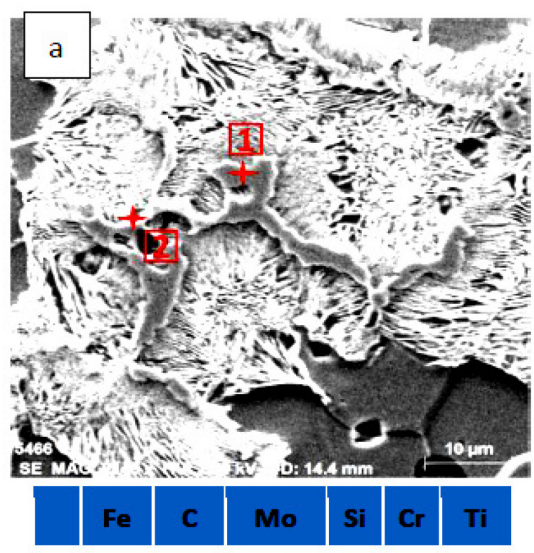

$\begin{array}{lllll}1 & 83.03 & 9.83 & 3.60 & 3.160 .38\end{array}$

$2 \begin{array}{llll}2 & 14.4520 .88 & 42.70 & 0.470 .4021 .11\end{array}$

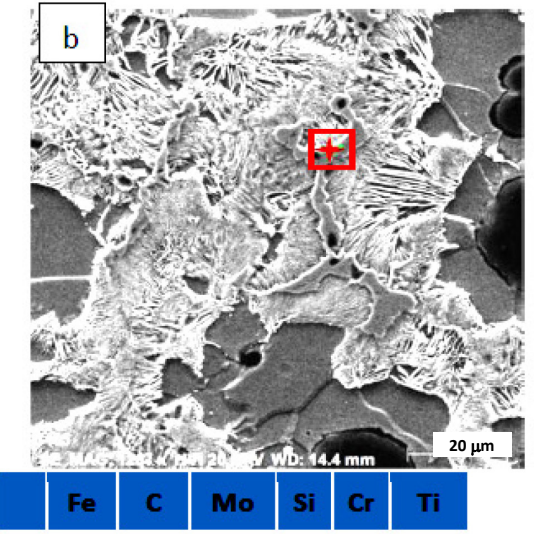

$164.0123 .43 \quad 9.99 \quad 1.900 .67$

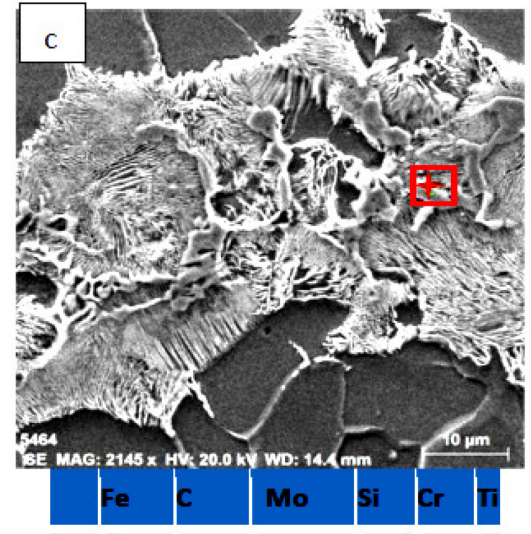

$171.4814 .93 \quad 10.48 \quad 2.101 .00-$

Fig 4: Composition of different eutectic carbides in SiMo 3-mm castings

\section{Nature of Fine Precipitates}

The cell-boundary components generally contain eutectic carbides embedded in the pearlite-like precipitate. Upon cooling to below eutectoid temperature, the fine precipitate, surrounding the eutectic carbides starts to form. The formation mechanism of these precipitates is still debatable. It may form due to:

i- $\quad$ Austenite decomposition upon cooling as one of the eutectoid transformation products.

ii- Pearlite decomposition subsequent to the pearlite reaction.

As indicated from Fig 1\&2 and table 1, the eutectoid reaction is followed by a peak on the DSC diagram at around $822{ }^{\circ} \mathrm{C}$, almost $86^{\circ} \mathrm{C}$ after the completion of the eutectoid reaction. Such peak is most probably related to the decomposition of pearlite $\rightarrow\left(\alpha+\mathrm{M}_{6} \mathrm{C}\right)$ subsequent to the eutectoid reaction.

Fig 5 shows that in the rapidly cooled alloy (3-mm section) the lamellar structure typical of pearlite seem to be in contact with the eutectic carbide phase, which may suggest nucleation of the precipitate phase on eutectic carbides. 


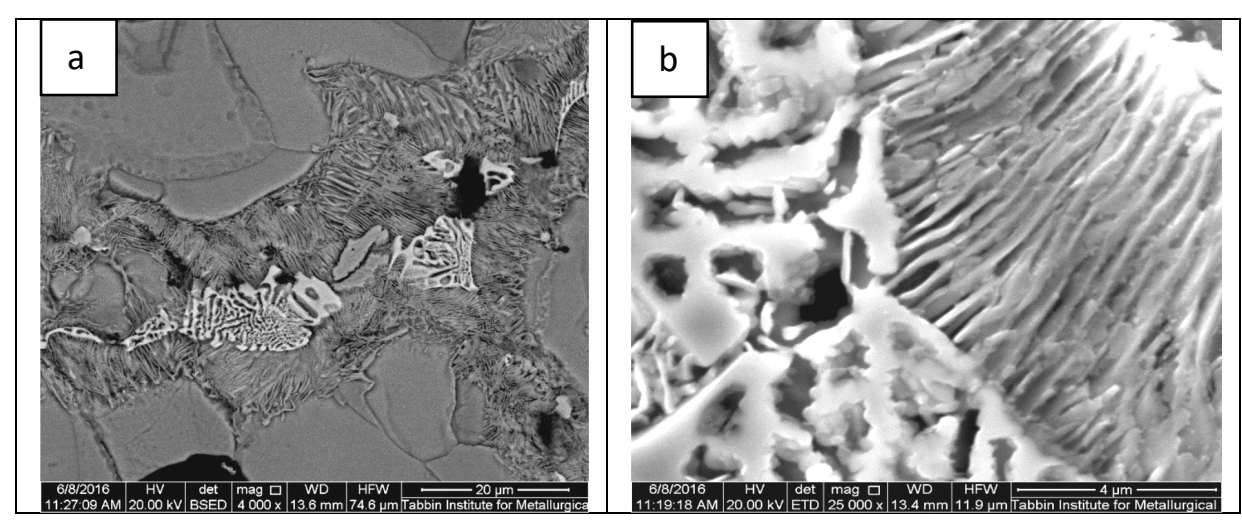

Fig 5: Nucleation of intercellular precipitates on eutectic carbides at low- and high-magnifications

For more accurate identification of the precipitate phase, both its composition and crystal lattice were determined [2], through analysis of particles in extraction replica applying selected area diffraction patterns (SADP) and convergent beam diffraction patterns (CBEP) using transmission electron microscopy. The results indicate a duplex-phase precipitate containing both $\mathrm{Fe}_{2} \mathrm{MoC}$ and $\mathrm{M}_{6} \mathrm{C}$ types were identified). The average analysis of the precipitate phase was found to be as follows: Fe: $68.7 \%$, Mo: $19.0 \%$, Si: $10.2 \%$ and Mn: $2.2 \%$.

In the present work, the rather fine structure of the precipitate made the compositional discrimination difficult due to the resolution limits. The sequence of precipitation of the two phases is still not clear and more investigations have to be carried out to understand whether the two carbide phases precipitate concurrently or sequentially, or one or both through decomposition of pearlite or whether one forms via the decomposition of the other.

\section{Nature of Fine Dispersed Precipitates}

With decreasing the cooling rate (9-mm sections - greensand), the pearlite noticed with the higher cooling rates (3-mm sections) partially decomposes to very fine precipitate (fig 6-a). Moreover, dispersed fine precipitates were noticed in the ferrite grains (fig $6-\mathrm{b}$ ). These dispersed precipitates may be related to the decrease in $\mathrm{C}$ and $\mathrm{Mo}$ - solubility in ferrite. The phase diagram shown in fig 1 suggests that those fine dispersed precipitates are of the $M_{7} C_{3}$ type of carbides that form around $200^{\circ} \mathrm{C}$ during cooling as indicated in the phase diagram. EDS analysis of those precipitates revealed that they contain low Mo-contents from 3.5-6.2\%, C-content from 11.2-13.0\%, Si-content from 2.1-2.8\% and Mn-content from 2.0-2.3\%.
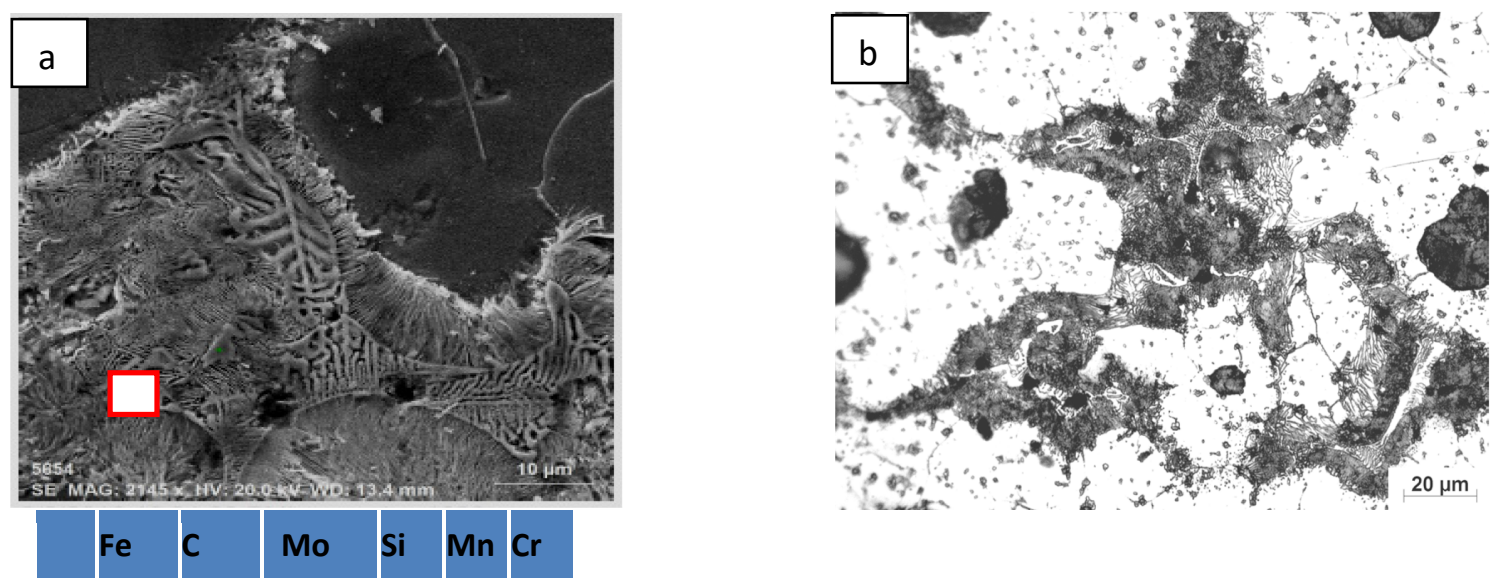

$\begin{array}{llll}1 & 51.0014 .44 & 28.50 & 4.321 .700 .03\end{array}$

Fig 6: Microstructure of 9-mm thick plate cast in green sand mold 


\section{Specimens Cast in Investment Molds}

\section{Nature of Eutectic Carbides}

The eutectic carbides formed in the rather slow cooled sections seem to be quite different in both composition and morphology. The slow solidification rates (9-mm thickness - investment mold) result in higher levels of segregation of Mo in the near vicinity of the intercellular zones. As a result, the eutectic carbides formed in those sections seem be higher in Mo-content. The morphology of the eutectic carbides may assume blocky or fish-bone morphologies as indicated in fig $(7 \mathrm{a}, \mathrm{b})$ respectively. In both cases, the Mo- content in the eutectic carbides was over $45 \%$.
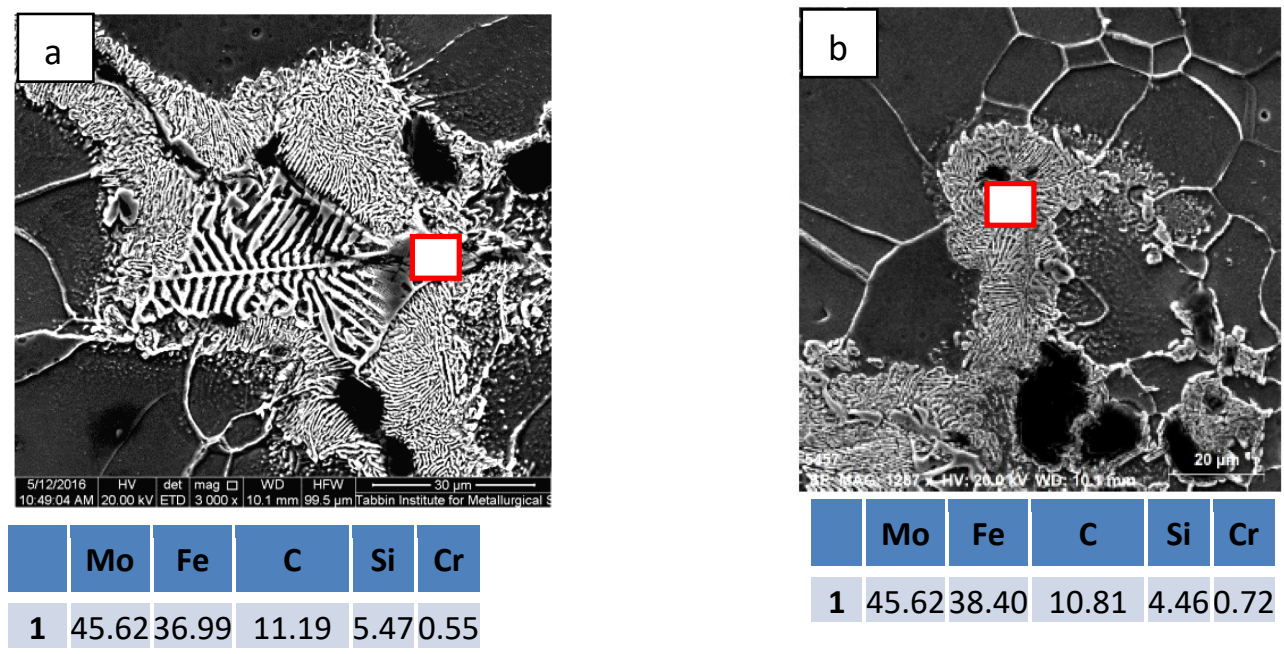

Fig 7: Intercellular eutectic and fine precipitates in the slowly cooled 9-mm thick investment mold plates

\section{Nature of Fine Precipitates}

Fig 8-a shows that the eutectic carbides formed in the highly Mo-segregated intercellular zones in the slowly cooled sections naturally contain higher contents $(\sim 48 \%)$ of Mo, whereas the rod-like precipitates formed in the very near vicinity contain much lower contents of about $2.15-2.57 \%$ Mo.

As in rapid cooling castings, the mixture of $\mathrm{Fe}_{2} \mathrm{MoC} / \mathrm{M}_{6} \mathrm{C}$ type carbides precipitates in the ferritic matrix at the intercellular regions (fig 8-b). As there are no grain boundaries between the precipitates and the ferrite grains, it is believed that the fine carbides precipitate within the ferrite after the proeutectoid and eutectoid reactions have occurred rather than form as a eutectoid transformation product. Most probably, the precipitate is formed through decomposition of the pearlite cementite surrounding the ferritic grains.
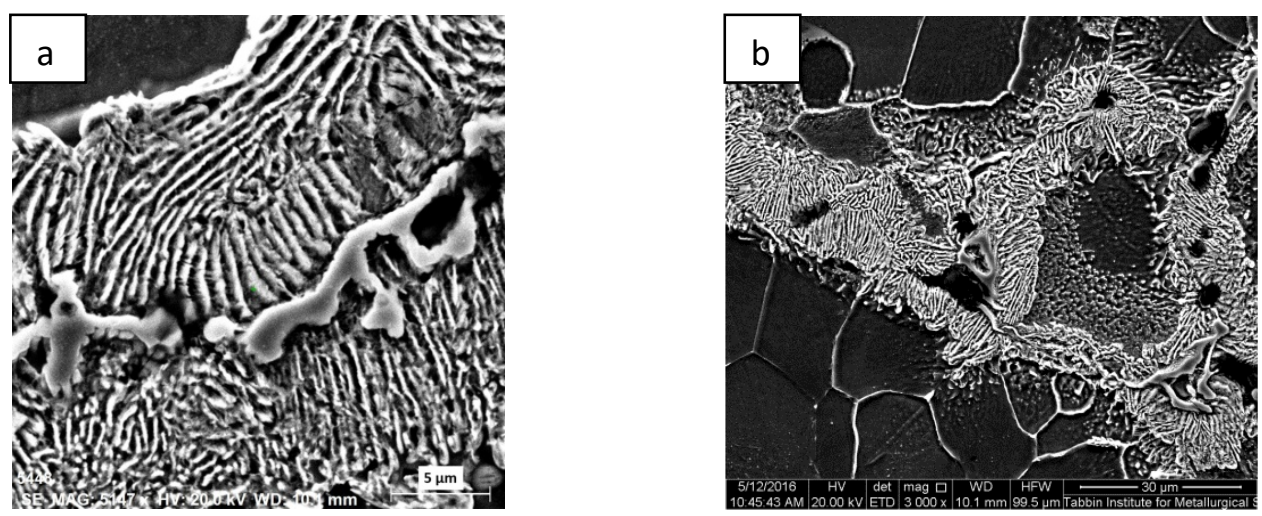

Fig 8: (a) Lower Mo-contents in the rod-like precipitate as compared to the eutectic carbides, (b) fine carbides precipitation within the ferrite grains 


\section{Chunky Graphite}

It is noteworthy to mention that, in some 9-mm thick sections cast in investment cast molds, chunky graphite was encountered in the intercellular regions. Chunky graphite is generally formed in slowly cooled castings, where solidification conditions promote the segregation of rare earth elements at the grain boundaries. This segregation is as well, enhanced by poor inoculation levels [7]. In our case, the precipitation of chunky graphite, concurrently with both blocky (fig 9- a) as well as fish bone (fig $9-$ b) eutectic carbides may be related to the higher Si-content in SiMo irons, higher accumulated levels of rare elements (RE) such as cerium added to the metallic charge as a component of the spheroidizing and inoculating addition, together with the slow solidification rates, which promote the segregation of RE to the intercellular regions.

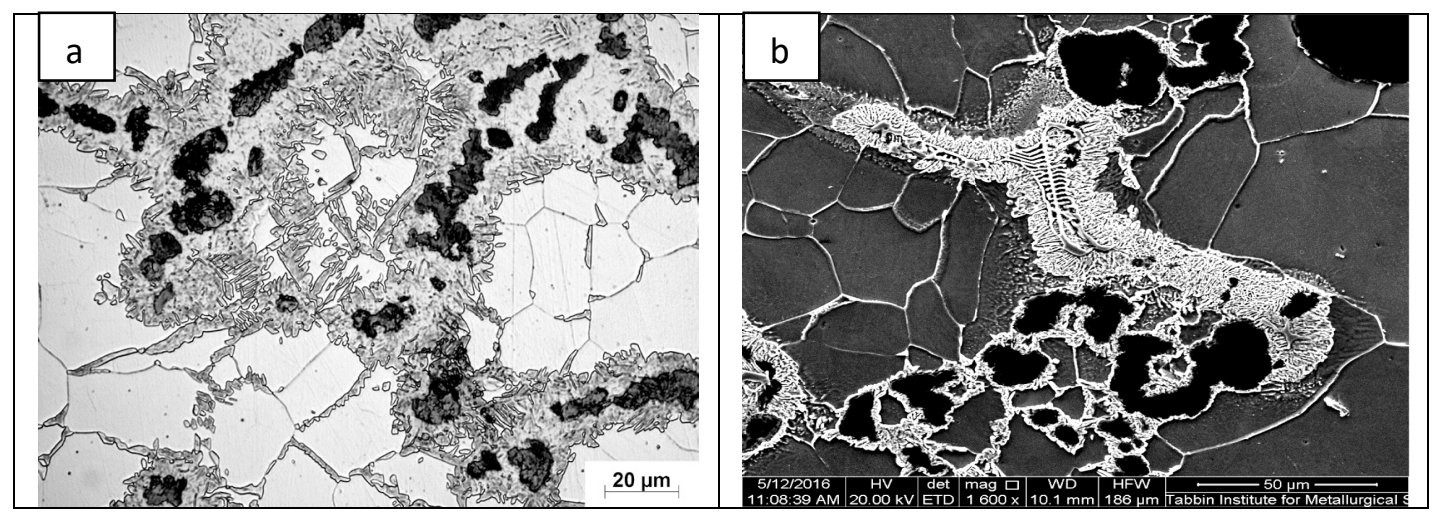

Fig 9: Formation of chunky graphite embedded in the intercellular regions.

\section{Comparison of Fine Precipitates in Different Cooling Rates}

Higher magnifications of the SEM reveal that the morphology of such precipitates is dependent on the solidification rate.

At higher cooling rates in castings of 3-mm thickness cast in greensand molds, the precipitate has lamellar structure typical of pearlite (fig 10- a), while at slower cooling rates in 9-mm thick investment cast sections, the precipitate has a rod-like shape (fig 10- b). In an earlier work [2], it has been assumed that the austenite transformation path starts with pearlite formation, and then subsequently followed by the decomposition of pearlite to the precipitate components with longer solidification time, associated with increasing section size.
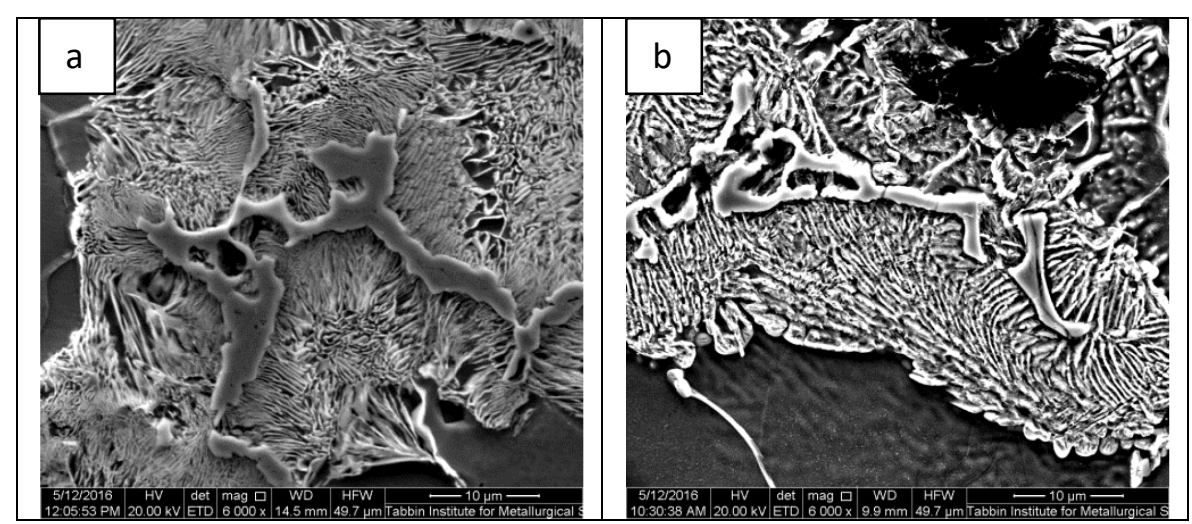

Fig 10: SEM of SiMo under different cooling rates (a) high cooling rate, 3-mm thick plates in greensand, (b) slow cooling rate, 9-mm thick plates in investment molds

\section{Conclusions}

1- The phase diagram of SiMo ductile irons containing 5\% Si and 0.7\% Mo was calculated from the Thermo-Calc software. Moreover, DSC cooling diagrams were studied. The data extracted from both diagrams were used to propose the solidification and solid-state phase transformation sequence. 
2- Two types of carbides have been detected in the microstructure of SiMo-irons. Eutectic carbides of $\mathrm{M}_{6} \mathrm{C}$ type were found embedded in a fine precipitate of $\mathrm{Fe}_{2} \mathrm{MoC} / \mathrm{M}_{6} \mathrm{C}-$ type carbides in the vicinity of the intercellular regions.

3- Analysis of DSC data revealed that the fine precipitate forms on cooling after the completion of proeutectoid and eutectoid reactions. It is suggested that the fine precipitate forms in ferrite as a consequence of pearlitic carbides decomposition.

4- The morphology and composition of the eutectic carbides vary with the cooling rate. At high cooling rates the eutectic carbides have the Chinese script morphology with wide spectrum of Mo-contents. With slower cooling rates, fish-bone structures are frequently encountered with higher Mo-contents, related to higher degrees of segregations associated with slow cooling.

5- The morphology and composition of the fine precipitate depend on the cooling rate of the casting. At rapid cooling, the precipitate has a lamellar structure, typical of pearlite, whereas at slower cooling rate, the precipitate has a spheroidal or rod-like structure.

\section{Acknowledgement}

This work was conducted in the frame of the research project: "Thin-wall iron castings for automotive applications" with very kind financial support of the Science and Technological Development Fund (STDF), the Ministry of Scientific Research of Egypt. The kind contribution of ELKEM by providing the inoculants used throughout this investigation is as well highly acknowledged.

\section{References}

[1] A. P. Druschitz, D. C. Fitzgerald, Lightweight Iron and Steel Castings for Automotive Applications, SAE Technical Paper 2000-01-0679.

[2] B. Black, G. Burger, R. Logan, R. Perrin, R. Gundlach, Microstructure and Dimensional Stability in Si-Mo Ductile Irons for Elevated Temperature Applications, SAE Paper No. 2002-012115.

[3] D. Li, R. Perrin, G. Burger, D. McFarlan, B. Black, R. Logan, R. Williams, Solidification behavior, microstructure, mechanical properties, hot oxidation and thermal fatigue resistance of high silicon SiMo nodular cast irons, No. 2004-01-0792, SAE Technical Paper, 2004.

[4] K. Choe, S. Lee, K. Lee, High Temperature Oxidation Behavior of Si-Mo Ferritic Ductile Cast Iron, Mater. Sci. Forum 654-656 (2010) 542-545.

[5] K. Choe, K. Lee and M. Kim, Effect of Mo on the microstructure and thermal expansion of high $\mathrm{Si}$ ferritic heat-resistant ductile iron, International Conference on Materials; Environmental and Biological Engineering (MEBE 2015).

[6] M. Stawarz, SiMo Ductile Iron Crystallization Process, Archives of Foundry Engineering 17 (1) (2017) 147-152.

[7] R. Logan, C. Hartung, A. Plowman, An investigation of chunky graphite defects in SiMo iron used for high temperature applications, Indian Foundry Journal 57 (5) (2011) 41-48. 